\title{
CLINICS
}

\section{Hypertension in special populations}

\author{
John M. Flack, MD, MPH ${ }^{\mathrm{a}, \mathrm{b}, *}$, Rosalind Peters, PhD, RN ${ }^{\mathrm{c}}$, \\ Vishal C. Mehra, MD ${ }^{\mathrm{d}}$, Samar A. Nasser, PAC \\ ${ }^{a}$ Department of Internal Medicine, Division of Endocrinology, Metabolism, and Hypertension \\ ${ }^{\mathrm{b}}$ Department of Community Medicine, Wayne State University and the Detroit Medical Center, \\ University Health Center, Suite 2E, 4201 St. Antoine, Detroit MI 48201, USA \\ ${ }^{\mathrm{c}}$ College of Nursing, Wayne State University, 5557 Cass Avenue, Detroit, MI 48202 \\ ${ }^{\mathrm{d}}$ Department of Internal Medicine, Division of General Internal Medicine Academic Hospitalist Program, \\ Wayne State University and the Detroit Medical Center, 4201 St. Antoine, Detroit, MI 48201, USA \\ ${ }^{\mathrm{e}}$ Department of Internal Medicine, Wayne State University and the Detroit Medical Center, 4201 St. Antoine, \\ Detroit, MI 48201, USA
}

Hypertension affects almost 50 million people in the United States. Although the threshold of elevated blood pressure (BP) traditionally has been $140 / 90 \mathrm{~mm} \mathrm{Hg}$, recent recommendations for high-risk patients, such as those with kidney disease, heart failure, coronary artery disease, diabetes mellitus, and heavy proteinuria, target $\mathrm{BP}$ levels well below $140 / 90 \mathrm{~mm} \mathrm{Hg}$. In this article, the special populations of children, pregnant women, African-Americans, kidney disease patients, posttransplantation patients, and individuals with diabetes mellitus are discussed. Emphasis is placed on unique aspects of the epidemiology, diagnostic criteria, and therapeutic approaches.

\section{Children}

Epidemiologic studies have identified a link between elevated BP in childhood and hypertension in adults [1-3]. In addition, obesity, a major risk factor for hypertension among children and adults, has dramatically increased in prevalence over the last three decades according to the Centers for Disease Control and Prevention (CDC) [4]. The definition of hypertension is based on the age- and gender-specific distribution of $\mathrm{BP}$

* Corresponding author. University Health Center, Suite 2E, Department of Internal Medicine, Wayne State University and the Detroit Medical Center, 4201 St. Antoine, Detroit, MI 48201.

E-mail address: jflack@intmed.wayne.edu (J.M. Flack). in healthy children, clinical experience, and clinical consensus $[5,6]$.

\section{Blood pressure measurement}

Children 3 years of age and older should have their BP measured at least twice and averaged, after a 5 minute rest, using the standard clinical sphygmomanometer, preferably in the right arm, with the stethoscope placed over the brachial artery approximately $2 \mathrm{~cm}$ above the cubital fossa [6]. Previously, diastolic BP (DBP) was determined by $\mathrm{K}_{4}$ ("muffling") in children 12 years of age or younger and $\mathrm{K}_{5}$ (disappearance of sound) in children 13 years of age and older [6,7]. An important change in the National High Blood Pressure Education Program (NHBPEP) 1996 update on the 1987 task force recommendations is that the fifth Korotkoff sound be used for all children, regardless of age [6]. In infants and children younger than 3 years of age Doppler ultrasound or oscillometric automated devices are more practical measurement modalities $[6,8]$. Ambulatory BP monitoring is predominantly a research tool in children because of a lack of standards in childhood despite some encouraging data regarding its benefits in detecting and managing childhood hypertension $[9,10]$.

\section{Etiology of hypertension in children}

Primary, or essential hypertension, which refers to elevated BP without evident cause, is a diagnosis 
that should not be applied in children until other potential causes have been excluded. Secondary hypertension is much more prevalent in children than among adults with hypertension. Therefore, attention must be given to identifying underlying disease processes contributing to the elevated BP.

Secondary hypertension occurs in $85 \%$ to $90 \%$ of all children with elevated BP. Renal artery obstruction secondary to thrombosis from umbilical artery catheterization is the most common cause of neonatal hypertension. Bronchopulmonary dysplasia, patent ductus arteriosus, and intraventricular hemorrhage are associated with neonatal hypertension [11]. Underlying renal disease is the most common cause of secondary hypertension in children younger than 13 years of age and is responsible for $70 \%$ to $80 \%$ of all cases of secondary hypertension in children [5,12]. Hypertension complicates almost $80 \%$ of all cases of acute poststreptococcal glomerulonephritis [5,12]. Chronic glomerulonephritis, reflux nephropathy, and renal artery stenosis are other renal causes of secondary hypertension in prepubertal children.

Coarctation of the aorta is the most common nonrenal secondary cause of hypertension, occurring in $5 \%$ to $15 \%$ of all cases of secondary hypertension in children [5]. Coarctation of the aorta, hyperthyroidism, and patent ductus arteriosus have been linked to isolated systolic hypertension, an uncommon BP phenotype in children [13]. Endocrinopathies-hyperthyroidism, hypercalcemia, adrenal cortical hyperplasia, or increased catecholamine production due to a pheochromocytoma-also must be considered as potential causes of elevated BP in children. Oral contraceptive use should be considered as a potential cause of elevated BP in adolescent girls. In older children, ingestion of sympathomimetics such as cocaine, amphetamines, or pseudoephedrine should be considered, particularly when there is concurrent evidence of sympathetic nervous system overactivity.

Primary or essential hypertension is rarely found in children younger than 10 years of age but is more frequent in later childhood and adolescence. Primary hypertension accounts for about $10 \%$ to $15 \%$ of all cases of hypertension in prepubescent children, but information regarding its incidence and overall prevalence in later childhood is lacking $[12,14]$.

Body size is a major determinant of $\mathrm{BP}$ among children [6], with obesity being a major modifiable risk factor for essential hypertension in children.
According to data from the National Health and Nutrition Examination Survey III (NHANES), $13 \%$ of children age 6 to 14 years and $14 \%$ of adolescents aged 12 to 19 years are overweight. This is double the number in NHANES II (1976-1980) and nearly triple the number who were overweight prior to 1976 [4].

In contrast to adults, among children there are minimal differences in BP between AfricanAmericans and whites. A review of eight large epidemiologic studies in children and adolescents $(\mathrm{N}=47,196)$ found few substantive differences in either systolic BP (SBP) or DBP [15]. Other risk factors such as low birth weight and exposure to environmental lead may predispose to development of premature onset hypertension. As with adults, socioeconomic status may be a factor in childhood hypertension especially as it relates to dietary and exercise patterns, probable body size, exposure to environmental toxins such as lead, and access to as well as utilization of health care.

\section{Diagnostic evaluation}

Patient history should include attention to measures of growth and development (e.g., failure to thrive, precocious puberty, delayed secondary sexual development), dietary intake, physical activity, recurrent urinary tract infections, exposure to nephrotoxic drugs (e.g., nonsteroidal antiinflammatory drugs [NSAIDs], ampethetamines, cocaine), and oral contraceptive use in girls. Family history of premature onset of hypertension, with or without early onset hemorrhagic stroke, is suggestive of glucocorticoid remedial aldosteronism (GRA). The physical examination should include abdominal assessment for flank masses or abdominal bruits, thyroid bruits, and comparison of lower extremity BP with arm BP as a screen for coarctation of the aorta.

For obese children with mild hypertension (at or just above 95th percentile) and a family history of hypertension, the NHBPEP guidelines recommend few diagnostic studies beyond urinalysis, blood urea nitrogen, and serum creatinine levels. Others have recommended additional studies such as uric acid and lipid levels [5,12]. Pregnancy tests should be considered for adolescent girls. When $\mathrm{BP}$ elevations are severe, priority is given to detailed assessment of the kidney anatomy and functioning, because as many as $80 \%$ of the children with hypertension have kidney parenchymal disease [5]. The plasma aldosterone:renin ratios as a screening test for mineralocorticoid hyperten- 
sion may be useful in selected cases. Elevated urinary 18-hydroxycorticosteroid excretion and/ or genetic testing for the chimeric 11-beta-hydroxylase-aldosterone synthase gene can make the diagnosis of GRA. The serum metanephrine : creatinine ratio is a useful screening test for suspected pheochromocytoma. Echocardiograms are helpful in the diagnosis of coarctation of the aorta and can also show a left ventricular mass/hypertrophy.

\section{Treatment of childhood hypertension}

Weight reduction and aerobic exercise are recommended for children with $\mathrm{BP}$ levels at the 90th percentile or higher $[5,12,13]$. Results of low sodium diets have been mixed [16-18], and potassium supplementation does not appear to lower BP effectively in children [19,20]. Nevertheless, dietary sodium intake in the United States far exceeds recommended physiologic requirements; thus, a reduction in dietary sodium is advisable. Aerobic exercise is an important adjunct to weight loss and BP reduction and can be safely instituted in asymptomatic children with uncomplicated hypertension. If there is insufficient response to lifestyle interventions, or if the child has severe hypertension, then antihypertensive drug therapy should be considered. The goal is to reduce the $\mathrm{BP}$ to below the 95th percentile [6]. Angiotensisconverting enzyme (ACE) inhibitors, $\beta$-blockers, diuretics, and calcium antagonists are options for initial therapy. ACE inhibitors and angiotensin receptor blockers may be particularly useful in children with kidney disease but, because of their teratogenic effects (after the first trimester), these drugs should be used with extreme caution in older girls who may be sexually active [6]. $\beta$-blockers may reduce exercise tolerance in physically active children and also can cause bronchospasm in patients with reactive airway disease $[5,14]$. Nevertheless, there is a lack of long-term outcome studies on the effects of antihypertensive drug therapy initiated during childhood [6].

\section{Pregnancy}

Hypertension is an important cause of maternal and fetal morbidity and mortality and complicates $6 \%$ to $8 \%$ of all pregnancies [21]. Severe, adverse complications of hypertension in pregnancy are cerebral hemorrhage, disseminated intravascular coagulation, hepatic failure, acute renal failure, and abruptio placentae. The underlying cause of the elevated BP appears to be more important to the pregnancy outcome than the elevated $\mathrm{BP}$ per se.

$\mathrm{BP}$ readings should be taken in the seated position at heart level with an appropriately sized cuff. Measurement of BP in the left, lateral recumbent position is no longer recommended as BP measurement in this position can produce spuriously low readings [22]. DBP should be reported as Korotkoff Phase V sound [21], as more recent work indicates that $\mathrm{K}_{5}$, not $\mathrm{K}_{4}$, is closer to the true DBP [23-25]. Although ambulatory BP monitoring has been used increasingly in pregnancy [26], its role in the routine management of pregnant women remains to be established.

\section{Blood pressure in normal pregnancy}

Profound changes in circulatory physiology occur during pregnancy. Peripheral resistance decreases by $25 \%$, blood volume increases by approximately $50 \%$ by the end of the second trimester, and cardiac output increases by about $35 \%$ to $50 \%$ above nonpregnant values during the first trimester [27,28]. Also, renal blood flow and the glomerular filtration rate rise significantly, and the renin-angiotensin-aldosterone system is activated, although there is resistance to the vasoconstrictive effects of angiotensin II [29]. The result of these changes is that first BP falls, with diastolic BP averaging $10 \mathrm{~mm} \mathrm{Hg}$ lower than nonpregnant values by midtrimester, and then increases slowly to nongravid levels during the third trimester [30].

\section{Classification of hypertension}

The US NHBPEP advocates the use of four categories: chronic hypertension; preeclampsiaeclampsia; preeclampsia superimposed on chronic hypertension; and gestational (transient) hypertension. Chronic hypertension is defined as elevated $\mathrm{BP}(\mathrm{SBP} \geq 140$ and/or $\mathrm{DBP} \geq 90 \mathrm{~mm} \mathrm{Hg}$ ) that was either present prior to conception or was detected before the 20th week of gestation and does not resolve after delivery. Preeclampsiaeclampsia is a systemic syndrome characterized by hypertension occurring after the 20th week of gestation and is usually, though not invariably, accompanied by proteinuria. Eclampsia is the convulsive phase of the disorder. Preeclampsia superimposed on chronic hypertension has a prognosis that is much worse than for either condition alone and can cause severe maternal and fetal complications [21]. It can be difficult to distinguish superimposed preeclampsia from an exacerbation 
of chronic hypertension with underlying kidney disease. Nevertheless, it is better to err on the side of caution and overdiagnose pre-eclampsia rather than to miss it [21]. Superimposed preeclampsia hypertension is highly likely in previously hypertensive women who have a new-onset of proteinuria ( $\geq 0.3 \mathrm{~g}$ protein in 24-hour urine specimen); in women with hypertension and proteinuria before 20 weeks' gestation; a sudden, precipitous increase in $\mathrm{BP}(>30 \mathrm{~mm} \mathrm{Hg}$ systolic or $>15 \mathrm{~mm} \mathrm{Hg}$ diastolic) in women with previously controlled hypertension; thrombocytopenia $(<100,000$ cells/ $\mathrm{mm}^{3}$ ) or abnormal alanine aminotransferase (ALT) or aspartate aminotransferase (AST) levels [21]. Gestational (transient) hypertension, a relatively benign condition, is elevated $\mathrm{BP}$ occurring without proteinuria with onset late in pregnancy or the early puerperium that resolves within 12 weeks of delivery.

\section{Management of chronic hypertension in pregnancy}

Generally, neither maternal nor fetal risks are increased in uncomplicated mild chronic hypertension. Most of the increased risk is associated with severe hypertension $(50 \%$ fetal loss for women with stage III hypertension) [31] or preeclampsia superimposed on the chronic hypertension [32]. There is some evidence that antihypertensive drug treatment may forestall progression to severe hypertension during pregnancy $[33,34]$; however, one retrospective study did not find that antihypertensive medications reduced the frequency of superimposed preeclampsia, preterm delivery, or abruptio placentae in treated versus untreated women [35], and there is no evidence that drug therapy improves neonatal outcomes [21]. Women with chronic hypertension may paradoxically experience an exaggerated fall in BP during the first two trimesters, which may permit discontinuation of their antihypertensive medication; however, antihypertensive therapy should be restarted if $\mathrm{BP}$ reaches 150 to $160 \mathrm{~mm} \mathrm{Hg}$ systolic and/or 100 to $110 \mathrm{~mm} \mathrm{Hg}$ diastolic [21].

\section{Antihypertensive medications during pregnancy}

Medication choices in pregnancy are more limited because of their potential teratogenic effects and the lack of randomized clinical trials in pregnant women. Many studies have initiated antihypertensive drug therapy in midgestation after the greatest risk of significant fetal deformity had passed. Thus, there are a small number of drugs qualifying for the Food and Drug Administration's Category A designation [36].

Methyldopa, a central adrenergic inhibitor, is the drug of choice for initial therapy in pregnancy. In addition to its long history of safety and effectiveness, it has been prospectively evaluated in randomized trials, including one 7-year followup of the children exposed in utero [37-39]. Hydralazine is the vasodilator of choice in acute hypertensive crises and also has been used successfully in the management of chronic hypertension. Calcium antagonists, particularly nifedipine, appears to be an effective, safe antihypertensive agent. Beta blockers are second line drugs and are mostly used late in pregnancy and have been linked to fetal growth retardation [40]. Alpha blockers are not recommended except in the rare case of hypertension secondary to pheochromocytoma [36]. Diuretics are not recommended as first-line therapy [21]. These agents may attenuate the normal increase in blood volume to normal pregnancy levels and therefore may retard fetal growth. Nevertheless, a meta-analysis found diuretics to be safe and efficacious except in cases in which uteroplacental blood flow is already reduced [21]. Thiazide diuretics are primarily used when they have been initiated prior to pregnancy. Furosemide, a loop diuretic, should be avoided because of potential embryotoxicity [41]. There are little data on antihypertensive medications during lactation. Animal studies suggest that these drugs are excreted through breast milk, and short-term studies have not found adverse effects from methyldopa or hydralazine on infants. ACE inhibitors and angiotensin receptor blockers are contraindicated in pregnancy [21] because they are associated with growth restriction, oligohydramnios, irreversible fetal/neonatal renal failure, and neonatal death $[21,42,43]$.

\section{Preeclampsia}

Clinicians should have a high index of suspicion for preeclampsia in women considered to be at greater risk for developing the condition. Risk factors include (1) nulliparity, (2) >40 years of age, (3) African-American race, (4) preexisting cardiovascular disease (CVD) (e.g., chronic hypertension, renal disease, diabetes mellitus), (5) multifetal pregnancy, (6) family history of pregnancy-induced hypertension, (7) previous preeclampsia if a multipara, (8) increased body size, and (9) higher prepregnancy level of SBP, DBP, or both. 
Pathophysiology of preeclampsia

Preeclampsia is a pregnancy-specific, multisystem disorder with both maternal and fetal manifestations that can be life-threatening even in the setting of modest BP elevations. Plasma volume is reduced, which can lead to decreased regional perfusion and hemoconcentration. Abnormal vascular responses appear to be related to increased sensitivity to pressor substances (eg, AII and endothelin), decreased endogenous vasodilators, and cytokine-induced endothelial cell damage [44]. Organ-selective vasoconstriction resulting in widespread microvascular cerebral changes and ischemia within the brain, not just the BP elevation per se, are believed to cause the seizures. Thrombocytopenia, probably attributable to platelet aggregation and deposition at sites of endothelial damage, has been observed [45]. Renal blood flow, glomerular filtration rate, and serum uric acid clearance all are reduced. Serum urate levels also may be elevated [21]. Liver injury as evidenced by elevated serum enzymes (aminotransferase and lactate dehydrogenate) or the HELLP syndrome (hemolysis, elevated liver enzymes, low platelets) may be present.

\section{Management of preeclampsia}

Virtually all interventions are designed to protect the mother while allowing time for fetal maturity and cervical ripening. Although delivery cures preeclampsia, its effect is not immediate and women remain at risk for continuing problems such as seizures up to 5 days postpartum. Hypertension and proteinuria may not remit for weeks. Nonpharmacologic interventions for preeclampsia include restricted physical activity. Close maternal and fetal surveillance is required. Initial in-patient management and evaluation is usually advisable [21]; however, home care and outpatient management may be acceptable for a select group of patients with mild preeclampsia who are remote from term [46-48]. Pharmacologic interventions for preeclampsia include antihypertensive and antiseizure medications. There are data that do and others that do not support the use of calcium supplementation [49,50], antihypertensive medication [39,51], and aspirin [52-54] for the prevention of preeclampsia [21]. Magnesium sulfate is effective in reducing the incidence of eclampsia in women with severe preeclampsia [55]; however, in women treated with calcium antagonists, precipitous falls in BP may occur after administration of magnesium sulfate [21].

\section{African-Americans}

African-Americans, as a group, have an earlier onset of hypertension, higher age-adjusted hypertension prevalence, and more BP-related targetorgan damage (ie, left ventricular hypertrophy, kidney disease) than age- and sex-matched whites $[56,57]$. The relative race differential in hypertension prevalence is most pronounced among those with the highest BP levels - almost 9\% of AfricanAmericans but fewer than $1 \%$ of whites having Joint National Committee (JNC) stage 3 hypertension $(\geq 180 / 110 \mathrm{~mm} \mathrm{Hg})$. An important point of emphasis, however, is that most differences in hypertension and pressure-related complications between African-Americans and whites appear to be quantitative not qualitative. That is, there is a higher burden of hypertension and pressurerelated complications among African-Americans compared to whites. The relationship of BP to demographic characteristics such as age and to CVD-renal endpoints over a wide range of BP, however, is remarkably similar [57,58]. Among African-Americans, hypertension accounts for a greater proportion of the overall mortality burden than it does in the white population. Nevertheless, in NHANES-1, the SBP logistic regression coefficient for total mortality was similar among African-American and white men but was slightly higher in white women than African-American women [59]. Additional analyses from this same longitudinal data set showed the higher relative risks of death associated with an SBP $\geq 140$ $\mathrm{mm} \mathrm{Hg}$ in African-Americans relative to whites was attributable to the greater prevalence of African-Americans with BP levels at or above this SBP level. The excess hypertension prevalence, in turn, accounted for $10 \%$ of the African-American mortality excess. Finally, heterogeneity in the risk for hypertension [60], the response to antihypertensive drug therapy [61], and the occurrence of pressure-related complications such as stroke $[62,63]$ and kidney disease [64] have been described within race and ethnic groups when these groups have been stratified either by geography, socioeconomic status, or dietary habits. These within-race differences are typically larger than previously described inter-race differences in these same outcomes.

\section{Treatment}

There appears to be no compelling reason(s) to believe that drug selection for African-Americans differ from other race or ethnic group unless 
dictated by clinical characteristics that can vary at the individual level. Therapeutic recommendations for African-American patients typically have been guided by overreliance on whether initial monotherapy with diuretic and calcium antagonist lowered BP more than other drug therapies such as ACE inhibitors and beta blockers. This therapeutic paradigm is flawed for at least two reasons. First, in trials in which diuretics and calcium antagonists have lowered BP more than other drugs, say ACE inhibitors, the average attained BP in all of the treatment groups typically remained significantly above 140/90 $\mathrm{mm} \mathrm{Hg}$. Accordingly, typically three to four drugs are needed to attain low therapeutic BP targets in high-risk hypertensive pateints. Second, the "only BP matters" therapeutic paradigm ignores the fact that antihypertensive drug therapy has been shown to protect target organs and reduce clinical events over and above what realistically can be attributed to BP lowering [65-67].

Another issue has been the utilization of known/ perceived racial (group level) differences that are extrapolated in blanket fashion to virtually all individuals in that group. Known or perceived pathophysiologic tendencies in hypertensive AfricanAmericans have led to overinterpretation of differences in BP responsiveness of AfricanAmericans and whites to drugs with their primary locus of action on the renin-angiotensin-aldosterone kinin (RAAK) system. For example, hypertensive African-Americans more so than whites manifest suppressed circulating renin activity. Many hypertensive African-Americans, however, have normal to high circulating renin activity. In addition, hypertensive African-Americans compared to whites do not appear to be plasma volume expanded [68]. Also, the control of renin secretion is complex and is not necessarily linked to plasma volume expansion in African-Americans with hypertension [69].

The linkage of lesser average BP responsiveness in African-Americans relative to whites to drugs primarily affecting the RAAK system because of the tendency toward suppressed circulating renin activity is flawed on several accounts. First, the implicit assumption that AfricanAmericans and white hypertensive study volunteers are similar is often incorrect. Prior to randomized treatment assignment in clinical trials, racial differences often exist-including different distributions of BP levels, different duration of $\mathrm{BP}$, differences in smoking status, and kidney function-all of which potentially confound the observed BP response differentials. These differences are rarely, if ever, adjusted for in the contrasts of BP responses between AfricanAmericans and whites. Furthermore, racial contrasts on BP response are virtually always post hoc comparisons of convenience samples that are outside the usual protections (ie, balancing of confounders) of the randomization procedure. Second, the differences in BP response, for example with ACE inhibitors, are most prominent at relatively low doses and either diminish markedly or disappear althogether with titration of the drug dose into the middle or upper part of the dosing range $[70,71]$. Third, relatively smaller differences in mean BP responsiveness between AfricanAmerican and white hypertensive patients have inexplicably overshadowed the much greater heterogeneity of BP response within racial groups. Moreover, some African-Americans have greater reduction in BP than whites to drugs such as ACE inhibitors and beta blockers despite that, on average, whites respond better at the group level. This paradox at the level of the individual occurs because the race-specific BP response distributions overlap each other. Finally, at least with ACE inhibitors, the pretreatment renin level does not predict BP response in African-Americans [72]. Thus, the totality of evidence provides compelling, albeit to a degree circumstantial, rationale against the long-held treatment paradigm of avoiding antihypertensive agents that primarily act on the reninangiotensin system on the presumption of lack of efficacy in either BP lowering or target-organ protection. Data from the ongoing ALLHAT trial [73] will likely provide even more answers regarding relative benefits of antihypertensive drugs, attained BP levels, and modifiers of these effects in AfricanAmerican hypertensive patients.

The recent interim analysis of the AfricanAmerican Study of Kidney Disease (AASK) trial provides important insights regarding the therapeutic selections and clinical characteristics influencing preservation of kidney function in African-Americans who have reduced kidney function attributable to hypertensive nephrosclerosis [74]. AASK was a $3 \times 2$ factorial design trial that randomized 1094 African-Americans with glomerular filtration rates (GFR) between 20 and $65 \mathrm{~mL} / \mathrm{min} / 1.73 \mathrm{~m}^{2}$ to treatment with amlodipine $(\mathrm{n}=217,5-10 \mathrm{mg} / \mathrm{d})$, ramipril $(\mathrm{n}=436$, $2.5-10 \mathrm{mg} / \mathrm{d})$, or metoprolol $(\mathrm{n}=441,50-200$ $\mathrm{mg} / \mathrm{d}$ ) with a usual mean arterial pressure (MAP) goal of 102 to $107 \mathrm{~mm} \mathrm{Hg}$ or to a low MAP goal of $\leq 92 \mathrm{~mm} \mathrm{Hg}$. Unblinded drug therapy was se- 
quentially added in the following order as necessary to achieve BP goals: (1) furosemide, (2) doxazosin, (3) clonidine, (4) hydralazine, and (5) minoxidil. The primary trial outcome was the rate of change in GFR and the main secondary outcome was the composite of a reduction in GFR $>50 \%$ or $25 \mathrm{~mL} /$ $\mathrm{min} / 1.73 \mathrm{~m}^{2}$, end-stage renal disease (ESRD), or death. After the initial 3 months of the trial, BP averaged 134.5/82 $(\mathrm{MAP}=99.8)$ and 132.9/81.4 $(\mathrm{MAP}=98.8) \mathrm{mm} \mathrm{Hg}$, respectively, in the ramipril and amlodipine treatment arms. Each group took an average of 2.75 drugs.

Although there was no difference among the treatment groups in the mean change in GFR over 3 years, compared to the amlodipine treatment arm, ramipril had a $36 \%$ slower decline in GFR after 3 months $(P=0.002)$ and a $38 \%$ lower risk of the composite clinical endpoint $(P=0.005)$, and less proteinuria $(P<0.001)$. These observations were accentuated in participants with urinary protein:creatinine ratio $>0.22(\sim 300 \mathrm{mg} / \mathrm{d})$. Over the entire 3 years the ramipril group had a 2.02 $\mathrm{mL} / \mathrm{min} / 1.73 \mathrm{~m}^{2}$ slower mean decline in GFR $(P=$ 0.006 ) and a $48 \%$ lower risk of the composite clinical endpoint. GFR remained higher over the 3 year follow-up in the amlodipine arm in participants with baseline urinary protein:creatinine ratio $\leq 0.22$ and among persons with baseline GFR $\geq 40$ $\mathrm{mL} / \mathrm{min} / 1.73 \mathrm{~m}^{2}$.

What is the clinical meaning of these results? First, these data confirm the previously reported benefits [75] in other populations of pharmacologic targeting of the RAAK system with ACE inhibitors in patients with reduced kidney function. In fact, AASK provides the first such tangible data to support of the previous speculations that we have previously put forth [76]. The relative superiority of the ACE inhibitor as initial therapy in African-Americans with kidney disease is somewhat ironic given the long held belief that calcium antagonists were preferred antihypertensive agents for African-Americans. This widely held treatment paradigm existed because among individuals treated with monotherapy, calcium antagonists lowered BP, on average, more effectively than ACE inhibitors. Third, these data provide evidence in African-Americans that the drug selection paradigm should clearly move away from solely being based on BP lowering efficacy of antihypertensive drugs. It is reasonable to ask if monotherapy with amlodipine, and by implication other dihydropyridine calcium antagonists, is contraindicated in African-Americans and other persons with hypertensive kidney disease?
There are, we believe, two important caveats regarding the interpretation of this study. Amlodipine was used without simultaneous pharmacologic targeting of the RAAK system. Also, the in-study average BP levels remained relatively high despite prescription of almost three antihypertensive drugs. Although AASK could not directly address the impact of amlodipine with concurrent pharmacologic targeting of the RAAK system, in at least one other study the ACE inhibitor was superior as monotherapy to amlodipine, but the combination of the ACE inhibitor and amlodipine was even better [77,78]. Thus, until more data become available, a reasonable integration of the AASK data with the totality of evidence is that dihydropyridine calcium antagonists can be used in patients with kidney disease along with simultaneous pharmacologic blockade of the RAAK system. A further interpretation would be that aggressive BP lowering, even lower than that attained in AASK, should be the goal of therapy.

\section{Kidney disease}

Elevated BP commonly occurs in persons with kidney disease and, in turn, hypertension per se can cause a spectrum of mild-to-moderate kidney dysfunction that, if unabated, can ultimately result in ESRD and mortality attributable to kidney disease. Hypertension and diabetes mellitus are the two major causes of ESRD accounting for almost $60 \%$ of new ESRD cases per annum. ESRD rates are currently increasing $5 \%$ to $6 \%$ per annum. Type 2 diabetes mellitus has recently replaced hypertension as the primary cause of ESRD among African-Americans. Interestingly, obesity is a major risk factor both for hypertension and diabetes mellitus and, perhaps not coincidentally, has been linked to a multiplicity of changes in kidney neurohumoral and hemodynamic function that may contribute to the pathogenesis of kidney injury [79].

There are several important concepts for the practitioner who will be responsible for the care of patients with hypertension and kidney disease. First, the positive association of BP with risk of kidney failure and kidney disease mortality begins well within the so-called "normal" BP range $[58,64]$. Second, prospective pharmacologic BP lowering interventions with various combinations of antihypertensive drugs can slow the decline in GFR. BP levels as low as approximately $90 \mathrm{~mm}$ 
Hg MAP have been shown to provide incremental protection against the loss of kidney glomerular filtration [80]. It is patently unrealistic to think of attainment of low therapeutic BP targets $(<130 / 80-85 \mathrm{~mm} \mathrm{Hg})$ with antihypertensive monotherapy-combination therapy or "therapeutic cocktails" are the rule. The most recent BP target for persons with kidney disease [80] from the National Kidney Foundation (NKF) is $<130 / 80 \mathrm{~mm} \mathrm{Hg}$. The DBP target is more aggressive than the $<85 \mathrm{~mm} \mathrm{Hg}$ target recommended in the JNC VI report.

There are almost 6 million persons with serum creatinine levels $\geq 1.6 \mathrm{mg} / \mathrm{dL}$ or $\geq 1.4 \mathrm{mg} / \mathrm{dL}$ in men and women, respectively [81]. Usually serum creatinine levels have been used in clinical practice to identify person with reduced kidney function; however, moderate kidney dysfunction (estimated GFRs $<60 \mathrm{~mL} / \mathrm{min} / 1.73 \mathrm{~m}^{2}$ ) is easily missed, particularly in women, when relying solely on serum creatinine levels as an estimate of kidney function (Fig. 1). Arguably, the practitioner should be able to readily diagnose milder kidney dysfunction (estimated GFR $60-90 \mathrm{~mL} / \mathrm{min} / 1.73 \mathrm{~m}^{2}$ ). Unquestionably, the lack of recognition of moderate kidney dysfunction leads to uninformed clinical decision making. As a consequence, less than optimal therapeutic decisions are made, resulting in incomplete BP lowering and, ultimately, less than maximal preservation of kidney function. Box 1 displays the ways that lack of recognition of kidney dysfunction impedes optimal clinical decision making, therapeutic choices, and clinical outcomes. Importantly, the practitioner will set therapeutic BP targets higher than is recommended $(<130 / 80-85 \mathrm{~mm} \mathrm{Hg})$ when kidney dysfunction $\left(\leq 60 \mathrm{~mL} / \mathrm{min} / 1.73 \mathrm{~m}^{2}\right)$ remains undetected, a frequent occurrence when the serum creatinine level is used as the primary indicator of kidney function.

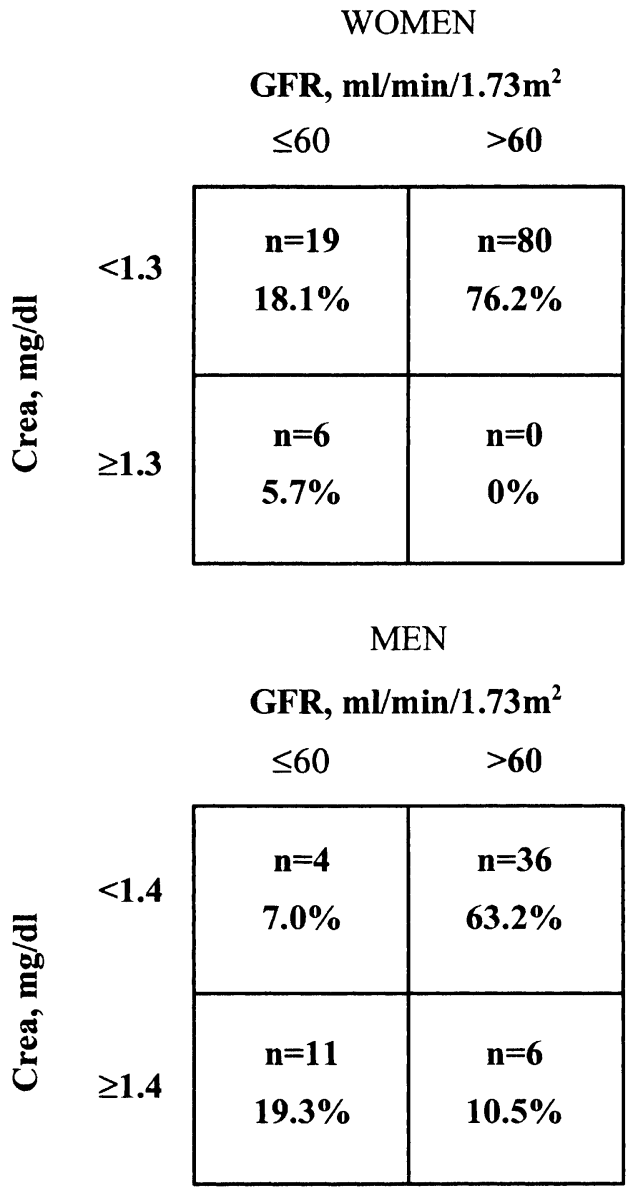

Fig. 1. Agreement between serum crea and EGFR.

\section{Treatment}

Patients with elevated BP and reduced kidney function are less often controlled to their goal BP than persons without kidney disease [82]. In

\section{Box 1. The impact of currently available indicators of kidney function on clinical decision-making and outcomes}

Serum creatinine is a clinically accepted, albeit gross indicator of kidney function although less accurate than other indicators

Inaccurate classification of kidney function directly impacts the following areas: appropriate BP targets ( $<140 / 90$ versus "lower") antihypertensive drug selection (eg, wrong diuretic) ancillary drug selection (eg, cavalier use of NSAIDs, glucophage) attention to "other" medical problems rate of loss of renal function prognostic regarding responsiveness to therapy 
addition, it is quite clear that multidrug therapy is required to achieve the low therapeutic goal BP levels. Diuretics are an indispensable component of the multidrug cocktail used to treat these patients, particularly when the patient is on more than two other antihypertensive drugs [83,84]. ACE inhibitors have been shown to slow the progressive loss of kidney function among people with either diabetic or nondiabetic kidney disease [85]. The protective effect appears to be most evident among persons with the most pretreatment proteinuria and the lowest level of kidney function $[86,87]$. These agents are profoundly antiproteinuric. Among individuals with milder reductions in kidney function, the risk of ischemic coronary and other cardiovascular events is significantly elevated. In the HOPE trial, individuals with serum creatinine $\geq 1.4$ to $2.3 \mathrm{mg} / \mathrm{dL}$ and without dipstick proteinuria had greater risk for CVD death $(11.4 \%$ versus $6.6 \%)$ and total mortality $(17.8 \%$ versus $10.6 \%)$. Among these patients, CVD, all-cause mortality, and heart failure hospitalizations were increased by twofold in persons with kidney insufficiency compared to those without reduced kidney function. Treatment with ramipril, an ACE inhibitor, reduced risk of the combined primary study endpoint-CVD death, myocardial infarction, or stroke-by $20 \%(95 \%$ $\mathrm{CI},-41 \%,+9 \%)$ among persons with kidney insufficiency [88]. There is emerging evidence that angiotensin receptor blockers provide similar kidney protection, at least in the setting of diabetic nephropathy. It should be remembered, however, that while drug selection is important, at the very minimum, the attainment of the goal BP also must be achieved to provide maximal protection against progressive loss of kidney function and to minimize nonkidney CVD sequelae.

\section{Therapeutic caveats}

Dietary sodium restriction is important because reduced kidney function leads to impaired natriuretic capacity. This combined with the use of vasodilator drugs can augment salt and water retention and, coupled with the relatively high amounts of sodium in the typical American diet, can lead to poor BP control and less than optimal reductions in proteinuria. Potassium-containing salt substitutes should be avoided in most patients with reduced kidney function. The use of nonsteroidal anti-inflammatory drugs (NSAIDs) can further reduce glomerular filtration, leading to salt and water retention, poor BP control, and even a tendency toward hyperkalemia, especially when other drugs that impair potassium secretion, such as ACE inhibitors, heparin, potassiumsparing diuretics, and to a lesser degree, angiotensin receptor blockers, are used simultaneously. The use of diuretics is essential in patients with kidney disease. Selection of the appropriate diuretic, however, is not always easy. When the estimated GFR is 50 $\mathrm{mL} / \mathrm{min} / 1.73 \mathrm{~m}^{2}$ or less, we avoid thiazide diuretics and use either zaroxolyn or furosemide. Furosemide, because of its short half-life, is most effective when used at least twice daily. Zaroxolyn is a longacting drug and can be effectively dosed once daily.

\section{Kidney function changes with treatment}

To put these recommendations into practice, clinicians should not let predictable changes in kidney function prevent them from choosing and maintaining the most appropriate therapy for persons with reduced kidney function. If BP elevations, the reduction in kidney function, or both are severe, a reduction in $\mathrm{BP}$ after initiation of pharmacologic therapy, even if ACE inhibitors or angiotensin receptor blockers are not used, will likely cause a transient rise in creatinine. ACE inhibitors initially cause a measurable fall in GFR [74]; however, over the long term, these agents markedly slow the progressive loss in kidney function. Bakris and Weir [86], in their excellent review of the subject, point out that the major reason for a rise in creatinine after initiation of ACE inhibitor therapy is volume depletion attributable to overdiuresis. In persons with critical bilateral renal artery stenosis, the use of ACE inhibitors also can cause a rise in creatinine. This is an infrequent cause, however, of rising creatinine levels after initiation of ACE therapy. Angiotensin receptor blockers can cause both elevations in creatinine and hyperkalemia similar to the ACE inhibitors but are less likely to do so.

\section{Posttransplantation}

Hypertension is quite common after solid organ transplantation and is more likely to be present if $\mathrm{BP}$ was elevated before transplantation. In fact, the relationship of elevated $\mathrm{BP}$ with transplantation is due in part to the fact that many transplants (eg, kidney) are performed in patients who were hypertensive prior to transplantation. A major reason for posttransplantation hypertension, however, is immunosuppressive therapy with the calcineurin inhibitors, cyclosporine and tacrolimus. 


\section{Epidemiology}

Since the advent of calcineurin use for posttransplant immunosuppression, the occurrence of posttransplant hypertension has risen. For example, posttransplant hypertension now complicates $67 \%$ to $90 \%$ of kidney transplants as compared to a $45 \%$ to $50 \%$ occurrence during the precyclosporine era $[89,90]$. Similar trends have been noted in recipients of bone marrow, livers, and hearts. Similar to the general population, hypertension is an important risk factor for CVD in kidney transplant recipients. The level of BP after transplant has been identified as an important determinant of kidney graft survival. Accordingly, in more than 29,000 kidney transplant recipients, Opelz and coworkers [91] found that 1-year graft survival was incrementally worse at SBP levels >139 $\mathrm{mm} \mathrm{Hg}$. The 24-hour BP burden also appears to be increased given the lack of nocturnal decline in BP; however, this abnormal diurnal variability in $\mathrm{BP}$ has been observed in persons with chronic kidney disease and therefore may antedate transplantation [92].

Overall mortality, CVD, or coronary risk is markedly increased in kidney transplant recipients. CVD accounts for almost $75 \%$ of posttransplantation mortality in kidney transplant recipients [93]. The 1997 USRDS data system [93] reports that kidney transplant recipients are 2.2 times more likely to die of CVD than the general population. Thus, the necessity of controlling $\mathrm{BP}$ as well as comprehensive management of other CVD risk factors to improve clinical outcomes is obvious.

\section{Causes of posttransplant hypertension}

Posttransplant hypertension can occur as a consequence of a broad range of causes. Obviously calcineurin inhibitors raise BP in the posttransplant period. Tacrolimus also causes posttransplant hypertension, although the data suggest that cyclosporine produces greater renal vasoconstriction and resultant systemic hypertension at an earlier onset than tacrolimus [94,95]. Furthermore, one study found higher serum creatinine and cholesterol levels among African-Americans taking cyclosporine versus tacrolimus 1 year after cadaveric kidney transplantation [96]. Concurrent use of corticosteroids also augments the risk of posttransplant hypertension. Other important causes, however, must be considered such as acute/chronic graft rejection, glomerulonephritis, renal artery stenosis, and hypertension attribut- able to the native kidney. Critical renal artery stenosis at the suture line in the grafted kidney occurs in about 1 in 50 transplants [97] and should be suspected when there is an abrupt rise in BP after transplantation. Atherosclerotic renal artery obstruction occurs many months to years after transplantation. Pretransplant hypertension has been linked to an increased risk of chronic graft rejection, which is a major cause of graft loss during the first year after transplantation. Focal glomerulosclerosis, a cause of kidney failure and transplantation, can recur in approximately $40 \%$ of kidney grafts [98]. In addition, focal sclerosis has been detected de novo in 30\% of patients with chronic allograft nephropathy [99]. Many patients will have reduced kidney function as evidenced by estimated GFRs $<60 \mathrm{~mL} / \mathrm{min} / 1.73 \mathrm{~m}^{2}$. Thus, they will have reduced natriuretic capacity and will likely be highly sensitive to dietary sodium. In addition, the median number of antihypertensive drugs required to achieve BP control after kidney transplantation is two when serum creatinine is $<1.3 \mathrm{mg} / \mathrm{dL}$ and increases to four when serum creatinine is between 1.3 and 2.0 $\mathrm{mg} / \mathrm{dL}[90]$.

\section{Mechanisms of calcineurin hypertension/cardiovascular toxicity}

These agents increase sympathetic nervous system activity [100], blunt the natriuretic response to volume expansion, cause vasoconstriction, and augment the effect of other endogenous vasoconstrictors. Cyclosporine augments proximal tubular reabsorption of sodium. Cyclosporine appears to unfavorably alter the balance of endogenous vasodilators and vasocontrictors as it decreases cyclic guanosine monophosphate (cGMP) production [101] either via decreased nitric oxide (NO) production and/or disturbed signal transduction from NO to cGMP [102]. Furthermore, cyclosporine causes dose-related increases in the potent vasoconstrictor endothelin [103] along with increased urinary excretion of thromboxane $A_{2}$, a vasoconstrictor prostaglandin $[104,105]$.

Cyclosporine can cause kidney damage at multiple foci: the arterioles, glomeruli, and interstitium. Glomerulonephritis, interstitial fibrosis, and arteriopathy all have been described [106]. Cyclosporine also causes in intense constriction of the glomerular afferent arteriole, a potentially important consideration in the selection of drugs, lifestyle modifications, and therapeutic BP targets in this high-risk patient population. 


\section{Treatment}

In patients with functioning kidney transplants it seems prudent to control BP aggressively to levels that are at least as low those recommended for persons with kidney disease $(<130 / 80-85$ $\mathrm{mm} \mathrm{Hg}$ ). One important consideration is that these patients have only a solitary functioning kidney. There are, in addition, several important therapeutic caveats to consider. Sodium restriction can augment BP response to most antihypertensive drugs, particularly in the setting of reduced kidney function, ad lib sodium intake, and vasodilator therapy, as the latter augments salt and water retention by the kidney. One must be careful with the transplant patient on cyclosporine, however, to avoid excessive sodium restriction and/or diuresis, both of which can lead to further reductions in GFR as well as augment cyclosporine nephrotoxicity. Cyclosporine-treated patients also are prone to developing hyperkalemia. Calcium antagonists are attractive antihypertensive agents in this population because they cause glomerular afferent arteriolar dilatation thus reversing the intense vasoconstriction caused by cyclosporine. Some calcium antagonists can, however, significantly raise cyclosporine levels, whereas others do not appear to. Amlodipine, diltiazem, nicardipine, and verapamil can cause substantial increases in cyclosporine levels; isradipine, nifedipine, and nitrendipine do not appear to do so. An additional theoretic concern with the calcium antagonists is that glomerular afferent arteriolar dilatation can result in direct transmission of systemic BP to glomeruli, resulting in damage, dysfunction, and over time, premature senescence. Thus, it is critically important to lower systemic BP to relatively low levels in the posttransplant population, particularly when using these agents. Finally, ACE inhibitors, angiotensin receptor blockers, and aldosterone receptor antagonists all have theoretic appeal in the posttransplant population because these drug classes antagonize/reverse target-organ injury responses (ie, fibrosis) as well as because of the favorable effects of ACE inhibitors and angiotensin receptor blockers on intraglomerular hemodynamics. Nevertheless, there are several important considerations when using ACE inhibitors and angiotensin receptor blockers. In transplant patients on cyclosporine with intense glomerular afferent arteriolar constriction, these agents can further depress GFR and elevate serum creatinine levels. Also, ACE inhibitors and angiotensin receptorblockers should be discontinued in patients with posttransplant renal artery stenosis because of the potential for deterioration in kidney function.

\section{Diabetes mellitus}

\section{Epidemiology}

Almost 16 million Americans have diabetes mellitus; 10.2 million of them are aware of their diagnosis [107]. Diabetes prevalence increases with advancing age and disproportionately affects racial and ethnic minority groups in the United States. Persons with type 2 diabetes have striking increases in absolute risk for micro- and macrovascular CVD-renal disease complications, with the relative increase compared to persons without diabetes being greater in women than men [108]. The risk of heart disease for people with diabetes mellitus increases approximately two to four fold over that for people without diabetes mellitus [107,108]. Approximately $75 \%$ of deaths among persons with diabetes are attributable to CVD. Lifetime risk of ESRD is increased relative to the general population at approximately $8 \%$, although the risk is much less than among persons with type 1 diabetes mellitus.

Hypertension in persons with diabetes mellitus is defined as $\mathrm{BP} \geq 130 / 85 \mathrm{~mm} \mathrm{Hg}$. People with diabetes mellitus are more likely to have hypertension than the general population in part because of common risk factors such as obesity, physical inactivity, and advanced age. Fifty-five percent to $65 \%$ of people with diabetes mellitus also have hypertension. Although most hypertension among persons with diabetes mellitus is "essential," the clinician should be aware of the potential superimposition of critical renal artery stenosis (of atherosclerotic origin) or renovascular hypertension upon long-standing essential hypertension because of the propensity to develop atherosclerosis in this high-risk population. The lower BP threshold for the diagnosis of diabetes mellitus is more than justified by the higher absolute CVD and mortality risks in persons with type 2 diabetes mellitus [109-111] and the proven benefit of BP lowering in placebo-controlled trials with both diuretic-based [108] and dihydropyridine calcium antagonist-based therapeutic regimens [111-113] in reducing the risk of microvascular and macrovascular complications. In addition, the diureticbased Hypertension Detection and Follow-up Program (HDFP) documented a reduction in CVD risk among persons with diabetes in those 
treated with the diuretic-based stepped care regimen compared to referred care [110]. Nevertheless, many if not most patients with diabetes mellitus require combination drug therapy to achieve target BP levels irrespective of the initial therapy chosen [109,112,114,115]. BP control rates to $<130 / 85 \mathrm{~mm} \mathrm{Hg}$ are abysmally low at $11 \%$.

\section{Active drug treatment trials}

There has been considerable debate and controversy regarding which drug class conferred the greatest risk reduction to hypertensive persons with type 2 diabetes mellitus. Furthermore, the published data in this area have been conflicting, at least to a degree. The landmark United Kingdom Prospective Diabetes Study Group study [115] over a median follow-up of 8.4 years found no difference in BP lowering efficacy or frequency of hypoglycemic events or in the incidence of diabetes-related complications, myocardial infarction, stroke, or total mortality between antihypertensive drug regimens starting with captopril, 25 $\mathrm{mg}$ twice a day, or atenolol, $50 \mathrm{mg}$ once daily [115]; however, atenolol-treated patients gained more weight and more often required additional glucose lowering therapy than those treated with captopril. The Hypertension Optimal Treatment (HOT) trial of hypertension provided important information regarding the importance of low target BP levels for persons with type 2 diabetes mellitus on active antihypertensive drug therapy [112]. HOT randomized more than 19,000 patients aged 50 to 80 years with DBPs of 100 to $115 \mathrm{~mm}$ $\mathrm{Hg}$ to one of three target DBP levels: $\leq 90, \leq 85$, or $\leq 80 \mathrm{~mm} \mathrm{Hg}$. Follow-up averaged 3.8 years. All patients received treatment initially with felodipine, $5 \mathrm{mg}$ once daily, with ACE inhibitors, beta-blockers, and diuretics used as add-on therapy to achieve target DBP levels. Amongst those with diabetes mellitus, major cardiovascular events and CVD mortality were incrementally and significantly lowered across the DBP strata. There was a $51 \%$ reduction in major CVD events at the lowest target DBP level of $\leq 80$ as compared to the CVD events at $\leq 90 \mathrm{~mm} \mathrm{Hg}$. Low dose aspirin was effective in reducing both myocardial infarction and major CVD event rates. Thus, these data with dihydropyridine-based therapy conclusively show the value of lower therapeutic target BP levels among hypertensive persons with diabetes mellitus. The Captopril Prevention Project (CAPP) study compared a captopril-based regimen to conventional therapy with diuretics and/or beta blockers in almost 11,000 men and women aged 25 to 66 years with DBP $\geq 100 \mathrm{~mm}$ $\mathrm{Hg}$ [116]. Add-on therapy in the captopril group after attainment of the maximal dose of $100 \mathrm{mg} / \mathrm{d}$ was a diuretic. Calcium antagonists were used as add-on therapy in both groups. Follow-up averaged 6.1 years. Among individuals with diabetes mellitus, there were $66 \%$ fewer myocardial infarctions, $33 \%$ fewer cardiac events, and $41 \%$ lower rates of the aggregate primary endpoint of myocardial infarction, stroke or CVD death in the captopril group compared to the conventional therapy group. A fascinating observation was made regarding the influence of captopril, an ACE inhibitor, on the incidence of diabetes mellitus. There were $21 \%$ fewer new cases of diabetes mellitus in the captopril group compared to the conventional therapy group. Data from CAPP suggests that ACE inhibitor-based therapy might be superior to initial therapy with diuretics and beta blockers and further suggests that ACE inhibitors might prevent new cases of diabetes mellitus.

The data supporting the role of ACE inhibitors as the preferred drug therapy among individuals with diabetes mellitus has come from both placebo-controlled trials and trials comparing ACE inhibitors to other active therapies. Several studies have contrasted the ACE inhibitors and dihyrdropyridine calcium antagonists as initial therapy in persons with type 2 diabetes mellitus and hypertension. These studies, Fosinopril versus Amlodipine Cardiovascular Events trial (FACET) [78] and the Appropriate Blood Pressure Control in Diabetes (ABCD) [117] trial, both showed that initial therapy with ACE inhibitors conferred greater protection against CVD morbidity and mortality than initial therapy with a dihydropyridine calcium antagonist. In the ABCD trial, risk of myocardial infarction was 9.5 -fold higher with nisoldipine than enalapril, although there was no difference observed in stroke, heart failure, CVD mortality, or all-cause mortality incidence. Data from the placebo-controlled MICRO-HOPE study were quite compelling [118]. Almost 3600 persons with diabetes mellitus (plus one other CVD risk factor or a prior CVD event) aged 55 years and older were enrolled in the HOPE trial and randomly allocated to ramipril, an ACE inhibitor, or placebo. Follow-up averaged 4.5 years. BP was $2.4 / 1.1 \mathrm{~mm} \mathrm{Hg}$ lower in the ramipril compared to the placebo group. The risk of the combined primary outcome of myocardial infarction, stroke, or CVD death was $25 \%$ lower in the ramipril group. Adjustment for the BP difference between the ramipril and placebo groups did not 
change this risk reduction. Persons with and without microalbuminuria as well as with and without hypertension appeared to benefit from ramipril treatment. Incidence of myocardial infarction, stroke, CVD death, revascularization, total mortality, and overt nephropathy all were lower, to a statistically significant degree, in the ramipril group. These data strongly suggest that ACE inhibitor treatment reduced the incidence of micro- and macro-vascular events in people with diabetes mellitus to a degree that was unexplained by lower BP in the ramipril group.

\section{Studies in normotensive individuals}

In addition to studies previously mentioned that enrolled at least some normotensive people, there are other studies suggesting benefit of ACE inhibitor therapy among normotensive persons with diabetes mellitus. Although conducted among individuals with type 1 diabetes mellitus, the administration of captopril compared to placebo appeared to lower the risk of ESRD and mortality among normotensive patients given captopril compared to placebo [66]. Other studies in normotensive persons with type 2 diabetes have documented that ACE inhibitor therapy can prevent the development of microalbuminuria in persons initially free of microalbuminuria prior to treatment [119] and can retard the progression from microalbuminuria to overt nephropathy [64]. ACE inhibitors administered after myocardial infarction also appear to reduce 6-week mortality in persons with type 2 diabetes mellitus [120]. These data provide some support for the use ACE inhibitors in normotensive persons with diabetes mellitus for the secondary prevention of target-organ damage.

\section{Therapeutic recommendations}

ACE inhibitors are preferred drugs in diabetic patients with hypertension and even merit strong consideration among those who are normotensive. Angiotensin receptor blockers are gaining favor, particularly for patients with diabetic nephropathy. Attainment of goal BP levels, at the very minimum, is a critical means of protection against the excess morbidity and mortality associated with diabetes mellitus; however, BP control is unlikely to occur in most persons with diabetes without combination drug therapy. The data regarding the benefit of dihydropyridine calcium antagonist in persons with type 2 diabetes are compelling in placebo-controlled trials. In relative terms, however, ACE inhibitors appear to provide better CVD protection than dihydropyridine calcium antagonists and conventional therapy with diuretics and beta blockers when directly compared. Angiotensin receptor blockers also appear to protect the kidney better than dihydropyridine calcium antagonists. A reasonable interpretation of the available data seems to be that long-acting dihydropyridine calcium antagonists are safe and effective in diabetes mellitus. Their biggest use, however, will be in persons already treated with ACE inhibitors or angiotensin receptor blockers. Another compelling lesson from the clinical trials in hypertensive persons with type 2 diabetes mellitus has been that risk reduction observed with a wide variety of mechanistically dissimilar drug classes highlights the important role of $\mathrm{BP}$ reduction in reducing risk in this high-risk population.

\section{References}

[1] Berenson GS, Wattigney WA, Bao W, Srinivasan SR, Radhakrishnamurthy B. Rationale to study the early natural history of heart disease: the Bogalusa Heart Study. Am J Med Sci 1995; 130(Suppl):522-8.

[2] Donahue RP, Prineas RJ, Gomez O, Hong LP. Tracking of elevated systolic blood pressure among lean and overweight adolescents: the Minneapolis children's blood pressure study. J Hypertens 1994; 12:303-8.

[3] Luepker RV, Jacobs DR, Prineas RJ, Sinaiko AR. Secular trends of blood pressure and body size in a multi-ethnic adolescent population: 1986-1996. J Pediatr 1999;134(6):668-74.

[4] Centers for Disease Control. NHANES III. Prevalence of overweight among children and adolescents: United States, 1999. Atlanta, GA: Centers for Disease Control; 2001. Available at: http:/ www.cdc.gov/nchs/products/pubs/pubd/hestats/over wght99.htm. Accessed July 18, 2001.

[5] Buzzard CJ, Lipshultz SE. High blood pressure in infants, children, and adolescents. In: Hoekelman RA, editor. Primary pediatric care. 4 th edition. St. Louis: Mosby; 2001. p. 1142-9.

[6] Update on the task force report. On blood pressure in children and adolescents: a working group report from the National High Blood Pressure Education Program. Bethesda, MD: 1996. NIH Publication 96-3790.

[7] Perloff D, Grim C, Flack J, Frohlich ED, Hill M, McDonald M, et al. Human blood pressure determination by sphygmomanometry. Circulation 1993; 88(5)2460-70.

[8] Groble MM. Hypertension in infancy. Pediatr Clin N Amer 1993;40:105-23. 
[9] Fernandes E, McCrindle BW. Diagnosis and treatment of hypertension in children and adolescents. Can J Cardiol 2000;16(6):801-11.

[10] Flynn JT. Impact of ambulatory blood pressure monitoring on the management of hypertension in children. Blood Press Monit 2000;5:211-6.

[11] Singh HP, Hurley M, Myers TG. Neonatal hypertension: incidence and risk factors. Am J Hypertens 1992;5:51-5.

[12] Sinaiko AR. Hypertension in children. N Eng J Med 1996;355:1968-73.

[13] Falkner B. Management of hypertensive children and adolescents. In: Izzo JL Jr, Black HR, editors: Hypertension prime. 2nd edition. Dallas: American Heart Association; 1999. p. 424-6.

[14] Pruitt AW. Systemic hypertension. In: Behrman RE, editor. Nelson Textbook of Pediatrics. 15th edition. Philadelphia: W.B. Saunders Co; 1996. p. 1368-74.

[15] Rosner B, Prineas R, Daniels SR, Loggie J. Blood pressure differences between blacks and whites in relation to body size among US Children and adolescents. Am J Epidemiol 2000;151:1007-19.

[16] Cooper R, Van Horn L, Liu K, Trevisan M, Nanas $\mathrm{S}$, Ueshima $\mathrm{H}$, et al. A randomized trial on the effect of decreased dietary sodium intake on blood pressure in adolescents. J Hypertens 1984;2:361-6.

[17] Gillum RF, Elmer PJ, Prineas RJ. Changing sodium intake in children. The Minneapolis Children's Blood Pressure Study. Hypertension 1981;3:698-703.

[18] Miller JZ, Weinberger MH, Daugherty SA, Fineberg NS, Christian JC, Grim CE. Blood pressure response to dietary sodium restriction in health normotensive children. Am J Clin Nutr 1988;47:113-9.

[19] Miller JZ, Weinberger MH, Christian JC. Blood pressure response to potassium supplementation in normotensive adults and children. Hypertension 1987;10:437-42.

[20] Sinaiko AR, Gomez-Marin O, Prineas RJ. Effect of low sodium diet or potassium supplementation on adolescent blood pressure. Hypertension 1993;21 (6 Pt 2):989-94.

[21] National Institute of Health. Working Group Report on high blood pressure in pregnancy. Bethesda: National Institutes of Health 2000. NIH Publicatin 00-3029.

[22] Barron WM, Lindheimer MD. Effect of oral protein loading on renal hemodynamics in human pregnancy. Am J Physiol 1995;269(4 Pt 2):R888-95.

[23] Blank SG, Helseth G, Pickering TG, West JE, August P. How should diastolic blood pressure be defined during pregnancy? Hypertension 1994;24:234-40.

[24] Brown MA, Buddle ML, Farrell T, Davis G, Jones M. Randomised trial of management of hypertensive pregnancies by Korotkoff phase IV or phase V. Lancet 1998;351:777-81.

[25] Johenning AR, Barron WM. Indirect blood pressure measurement in pregnancy: Kortokoff phase 4 vs phase 5. Am J Obstet Gynecol 1992;167: 573-80.
[26] Mermida RE, Ayala DE. Diagnosing gestational hypertension and preeclampsia with the 24 hour mean of blood pressure. Hypertension 1997;30:1-7.

[27] Poppas A, Shroff SG, Korcarz CE, Hibbard JU, Berger DS, Lindheimer MD, et al. Serial assessment of the cardiovascular system in normal pregnancy. Circulation 1997;95:2407-15.

[28] van Oppen AC, Stigter RH, Bruinse HW. Cardiac output in normal pregnancy: a critical review. Obstet Gynecol 1996;87:310-8.

[29] Sturgiss SN, Wilkinson R, Davison JM. Renal reserve during human pregnancy. Am J Physiol 1996;271(1 Pt 2):F16-20.

[30] Walters BN, Thompson ME, Lee A, de Swiet M. Blood pressure in the puerperium. Clin Sci 1986;71: 589-94.

[31] Sibai BM, Anderson GD. Pregnancy outcome of intensive therapy in severe hypertension in first trimester. Obstet Gynecol 1986;67:517-22.

[32] Sibai BM, Lindheimer MD, Hauth J, Caritis S, Van Dorsten P, Klebanoff M, et al. Risk factors for preeclampsia, abruptio placentae, and adverse neonatal outcomes among women with chronic hypertension. N Engl J Med 1998;339:667-71.

[33] Sibai BM. Treatment of hypertension in pregnant women. N Engl J Med 1996;335:257-65.

[34] Sibai BM, Mabie WC, Shamsa F, Villar MA, Anderson GD. A comparison of no medication versus methyldopa or labetalol in chronic hypertension during pregnancy. Am J Obstet Gynecol 1990;162:960-7.

[35] Rey E, Couturier A. The prognosis of pregnancy in women with chronic hypertension. Am J Obstet Gynecol 1994;171:410-6.

[36] Lindheimer MD, Akbari A. Hypertension in pregnant women. In: Oparil S, Weber MS, editors. Hypertension: A companion to Brenner and Rector's: The kidney. Philadelphia: W.B. Saunders Co; 2000. 688-701.

[37] Cockburn J, Moar VA, Ounsted M, Redman CW. Final report of study on hypertension during pregnancy the effects of specific treatment on the growth and development of children. Lancet 1982;1:647-9.

[38] Kyle PM, Redman CW. Comparative risk-benefit assessment of drugs used in the management of hypertension in pregnancy. Drug Saf 1992;7:223-34.

[39] Plouin PF, Breart G, Llado J, Dalle M, Keller ME, Goujon $\mathrm{H}$, et al. A randomized comparison of early with conservative use of antihypertensive drugs in the management of pregnancy induced hypertension. Br J Obstet Gynaecol 1990;97:134-41.

[40] Butters L, Kennedy S, Rubin PC. Atenolol in essential hypertension during pregnancy. BMJ 1990;301:587-9.

[41] Collins R, Yusuf S, Peto R. Overview of randomised trials of diuretics in pregnancy. BMJ 1985;290: 17-23.

[42] Hanssens M, Keirse MJ, Vankelecom F, Van Assche FA. Fetal and neonatal effects of treatment 
with angiotensin-converting enzyme inhibitors in pregnancy. Obstete Gynecol 1991;78:128-35.

[43] Piper JM, Ray WA, Rosa FW. Pregnancy outcome following exposure to angiotensin-converting enzyme inhibitors. Obstete Gynecol 1992;80:429-32.

[44] Baylis C, Beinder E, Suto T, August P. Recent insights into the roles of nitric oxide and reninangiotensin in the pathophysiology of preeclamptic pregnancy. Semin Nephrol 1998;18:208-30.

[45] Paidas MJ, Haut MJ, Lockwood CJ. Platelet disorders in pregnancy: implications for mother and fetus. Mt Sinai J Med 1994;61:389-403.

[46] Barton JR, Olson ML, Sibai BM. Monitored outpatient management of mild preeclampsia remote from term. Am J Obstet Gynecol 170:765-9.

[47] Crowther CA, Bouwmeester AM, Ashurst HM. Does admission to hospital for bed rest prevent disease progression or improve fetal outcome in pregnancy complicated by non-proteinuric hypertension? Br J Obstet Gynecol 1992;99:13-7.

[48] Tuffnell DJ, Lilford RJ, Buchan PC, Prendiville VM, Tuffnell AJ, Holgate MP, et al. Randomised controlled trial of day care for hypertension in pregnancy. Lancet 1992;339:224-7.

[49] Crowther CA, Hiller JE, Pridmore B, Bryce R, Duggan P, Hogue WM, et al. Calcium supplementation in nulliparous women for the prevention of pregnancy-induced hypertension, preeclampsia and preterm birth: an Australian randomized trial. FRACOG and the ACT Study Group. Aust N Z J Obstet Gynaecol 1999;39:12-8.

[50] Levine RJ, Hauth JC, Curet LB, Sibai BM, Catalano PM, Morris CD, et al. Trial of calcium to prevent preeclampsia. N Engl J Med 1997;337: 69-76.

[51] Redman CW. Controlled trials of antihypertensive drugs in pregnancy. Am J Kidney Dis 1991;17:149-53.

[52] Caritis S, Sibai B, Hauth J, Lindheimer MD, Klebanoff M, Thom E, et al. Low-dose aspirin to prevent preeclampsia in women at high risk. National Institute of Child Health and Human Development Network of Maternal-Fetal Medicine Units. N Engl J Med 1998;338:701-5.

[53] Hauth JC, Goldenberg RL, Parker CR Jr, Philips JB 3rd, Copper RL, Du Bard MB, et al. Low-dose aspirin therapy to prevent preeclampsia. Am J Obstet Gynecol 1993;168:1083-91; discussion 1091-3.

[54] Sibai BM, Caritis SN, Thom E, Klebanoff M, McNellis D, Rocco L, et al. Prevention of preeclampsia with low-dose aspirin in healthy, nulliparous pregnant women. The National Institute of Child Health and Human Development Network of Maternal-Fetal Medicine Units. N Engl J Med 1993;329:1213-8.

[55] Coetzee EJ, Dommisse J, Anthony J. A randomised controlled trial of intravenous magnesium sulfate versus placebo in the management of women with severe preeclampsia. $\mathrm{Br} \mathbf{J}$ Obstet Gynaecol 1998;105:300-3.
[56] Burt VL, Whelton P, Roccella EJ, Brown C, Cutler JA, Higgens M, et al. Prevalence of hypertension in the US adult population from the Third National Health and Nutrition Examination Survey, 19881991. Hypertension 1995;25:305-13.

[57] Flack JM, Gardin JM, Yunis C, Liu K. Static and pulsatile blood pressure correlates of left ventricular structure and function in black and white young adults: the CARDIA study. Am Heart J 1999;138(5 Pt 1):856-64.

[58] Flack JM, Neaton JD, Daniels B, Esunge P. Ethnicity and renal disease: lessons from the Multiple Risk Factor Intervention Trial and the Treatment of Mild Hypertension Study. Am J Kidney Dis 1993;21(4 Suppl 1):31-40.

[59] Cooper RS, Liao Y, Rotimi C. Is hypertension more severe among US blacks, or is severe hypertension more common? Ann Epidemiol 1996;6:173-80.

[60] Kiefe CI, Williams OD, Bild DE, Lewis CE, Hilner JE, Oberman A. Regional disparities in the incidence of elevated blood pressure among young adults: the CARDIA study. Circulation 1997;96:1082-8.

[61] Cushman WC, Reda DJ, Perry HM, Williams D, Abdellatif M, Materson BJ. Regional and racial differences in response to antihypertensive medication use in a randomized controlled trial of men with hypertension in the U.S. Department of Veterans Affairs Cooperative Study Group on Antihypertensive Agents. Arch Intern Med 2000;160:825-31.

[62] Anska DJ, Peterson PM. Geographic variation in the decline of stroke mortality in the United States. Stroke 1995;26:1159-65.

[63] Perry HM, Roccella EJ. Conference report on stroke mortality in the southeastern United States. Hypertension 1998;31:1206-15.

[64] Klag MJ, Whelton PK, Randall BL, Neaton JD, Brancati FL, Stamler J. End-stage renal disease in African-American and white men. 16- year MRFIT findings. JAMA 1997;277:1293-8.

[65] Ahmad J, Siddiqui MA, Ahmad H. Effective postponement of diabetic nephropathy with enalapril in normotensive type 2 diabetic patients with microalbuminuria. Diabetes Care 1997;20:1576-81.

[66] Lewis EJ, Hunsicker LG, Bain RP, Rohde RD. The effect of angiotensin-converting-enzyme inhibition on diabetic nephropathy: The Collaborative Study Group. N Engl J Med 1992;329:1456-62.

[67] Yusuf S, Sleight P, Pogue J, Bosch J, Davies R, Dagenais G. Effects of an angiotensin-convertingenzyme inhibitor, ramipril, on cardiovascular events in high-risk patients. The Heart Outcomes Prevention Evaluation Study Investigators. N Engl J Med 2000;342:145-53.

[68] Messerli FH, DeCarvalho JG, Christie B, Frohlich ED. Essential hypertension in black and white subjects. Hemodynamic findings and fluid volume state. Am J Med 1979;67:27-31.

[69] Chrysant SG, Danisa K, Kem DC, Dillard BL, Smith WJ, Frohlich ED. Racial differences in pressure, 
volume and rennin interrelationshps in essential hypertension. Hypertension 1979;1:136-41.

[70] Saunders E, Weir MR, Kong BW, Hollifield J, Gray $\mathrm{J}$, Vertes $\mathrm{V}$, et al. A comparison of the efficacy and safety of a beta- blocker, a calcium channel blocker, and a converting enzyme inhibitor in hypertensive blacks. Arch Intern Med 1990;150:1707-13.

[71] Weir MR, Gray JM, Paster R, Saunder E. Differing mechanisms of action of angiotensinconverting enzyme inhibition in black and white hypertensive patients. The trandolapril multicenter study group. Hypertension 1995;26:124-30.

[72] Weir MR, Saunders E. Renin status does not predict the anti-hypertensive response to angiotensin-converting enzyme inhibition in AfricanAmericans. Trandolapril Multicenter Study Group. J Hum Hypertension 1998;12:189-94.

[73] Grimm RH Jr, Margolis KL, Papademetriou VV, Cushman WC, Ford CE, Bettencourt J, et al. Baseline characteristics of participants in the antihypertensive and lipid lowering treatment to prevent heart attack trial (ALLHAT). Hypertension 2001;37:19-27.

[74] Agodoa LY, Appel L, Bakris GL, Beck G, Bourgoignie J, Briggs JD, et al. Effect of ramipril vs amlodipine on renal outcomes in hypertensive nephrosclerosis: a randomized controlled trial. JAMA 2001;285:2719-2728.

[75] Maschio G, Alberti D, Locatelli F, Mann JF, Motolese M, Ponticelli C, et al. Angiotensinconverting enzyme inhibitors and kidney protection: the AIPRI trial. The ACE Inhibition in Progressive Renal Insufficiency (AIPRI) Study Group. J Cardiovasc Pharmacol 1999;3351:S1620; discussion S41-3.

[76] Flack JM, Mensah GA, Ferrario CM. Using angiotensin converting enzyme inhibitors in African-American hypertensives: a new approach to treating hypertension and preventing target-organ damage. Curr Med Res Opin 2000;16(2):66-79.

[77] Sowers JR. Comorbidity of hypertension and diabetes: the fosinopril versus amlodipine cardiovascular events trial (FACET). Am J Cardiol 1998;82:15R-9R.

[78] Tatti P, Pahor M, Byington RP, Di Mauro P, Guarisco R, Strollo G, et al. Outcome results of the fosinopril versus amlodipine cardiovascular events randomized trial (FACET) in patients with hypertension and NIDDM. Diabetes Care 1998;21:597-603.

[79] All JE. Pathophysiology of obesity hypertension. Curr Hypertens Rep 2000;2:139-47.

[80] Bakris GL, Williams M, Dworkin L, Elliot WJ, Epstein M, Totu R, et al. Preserving renal function in adults with hypertension and diabetes: a consensus approach. National Kidney Foundation Hypertension and Diabetes Executive Committees Working Group. Am J Kidney Dis 2000;36:646-61.

[81] Coresh J, Wei GL, McQuillan G, Brancati FL, Levey AS, Jones C, et al. Prevalence of high blood pressure and elevated serum creatinine level in the
United States: findings from the third National Health and Nutrition Examination Survey (19881994). Arch Intern Med 2001;161:1207-16.

[82] Duncan K, Ramappa P, Thornburg R, et al. The influence of urinary albumin excretion and estimated glomerular filtration rate on blood pressure response in drug-treated hypertensive patients in an academic hypertension clinic. Am J Hypertension 2001;14(Suppl 2):196A.

[83] Flack JM, Bledsoe K. Combination antihypertensive drug therapy: a therapeutic option long overdue. Am Fam Physician 2000;6110:2974-7.

[84] Skolnik NS, Beck JD, Clark M. Combination antihypertensive drugs: recommendations for use. Am Fam Physician 2000;61:3049-56.

[85] Jafar TH, Schmid CH, Landa M, Giatras I, Toto R, Remuzzi G, et al. Angiotensin-converting enzyme inhibitors and progresssion of nondiabetic renal disease: a meta-analysis of patient-level data. Ann Intern Med 2001;135:73-87.

[86] Bakris GL, Weir MR. Angiotensin-converting enzyme inhibitor-associated elevations in serum creatinine: is this a cause for concern? Arch Intern Med 2001;160:685-693.

[87] Maschio G, Alberti D, Janin G, Locatelli F, Mann JF, Motolese M, et al. Effect of the angiotensinconverting-enzyme inhibitor benazepril on the progression of chronic renal insufficiency. N Engl J Med 1996;334:939-45.

[88] Mann JFE, Gerstein HC, Pogue J, Bosch J, Yusuf S. Renal insufficiency as a predictor of cardiovascular outcomes and the impact of ramipril: the HOPE randomized trial. Ann Intern Med 2001;134:629-36.

[89] Sorof JM, Sullivan EK, Tejani A, Portman RJ. Antihypertensive medication and renal allograft failure: a North American Pediatric Renal Transplant Cooperative Study report. J Am Soc Nephrol 1999;10:1324-30.

[90] Zeier M, Mandelbaum A, Ritz E. Hypertension in the transplanted patient. Nephron 1998;80:257-68.

[91] Opelz G, Wujciak T, Ritz E. Association of chronic kidney graft failure with recipient blood pressure. Kidney Int 1998;53:217-22.

[92] Rosansky SJ, Menachery SJ, Wagner CM, Jackson K. Circadian blood pressure variation versus renal function. Am J Kidney Dis 1995;26:716-21.

[93] Aakhus S, Dahl K, Wideroe TE. Cardiovascular morbidity and risk factors in renal transplant patients. Nephrol Dial Transplant 1999;14:648-54.

[94] Canzanello VJ, Textor SC, Taler SJ, Schwartz U, Porayko MK, Wiesner RH, et al. Late hypertension after liver transplantation: a comparison of cyclosporine and tacrolimus (FK 506). Liver Transpl Surg 1998;4:328-34.

[95] Radermacher J, Meiner M, Bramlage C, Kliem V, Behrend M, Schlitt HJ, et al. Pronounced renal vasoconstriction and systemic hypertension in renal transplant patients treated with cyclosporin A versus FK 506. Transpl Int 1998;11(1):3-10. 
[96] Raofi V, Holman DM, Coady N, Vazquez E, Dunn TB, Bartholomew AM, et al. A prospective randomized trial comparing the efficacy of tacrolimus versus cycolsporine in black recipients of primary cadaveric renal transplants. Am J Surg 1999;177:299-302.

[97] Merkus JW, Huysmans FT, Hoitsma AJ, Buskens FG, Skutnicki SH, Koene RA. Renal allograft artery stenosis: results of medical treatment and intervention. Transpl Int 1993;6:111-5.

[98] Banfi G, Colturi C, Montagnino G, Ponticelli C. The recurrence of focal segmental glomerulosclerosis in transplant patients treated with cyclosporine. Transplantation 1990;50:594-6.

[99] Cosio FG, Frankel WL, Pelletier RP, Pesavento TE, Henry ML, Ferguson RM. Focal segmental glomerulosclerosis in renal allografts with chronic nephropathy: implications for graft survival. Am J Kidney Dis 1999;34:731-8.

[100] Scherrer U, Vissing SF, Morgan BJ, Rollins JA, Tindall RS, Ring S, et al. Cyclosporine-induced sympathetic activation and hypertension after heart transplantation. N Engl J Med 1990;323:633-9.

[101] Rego A, Vargas R, Wroblewska B. Attenuation of vascular relaxation and cyclic GMP responses by cyclosporine A. J Pharmacol Exp Ther 1990;252: 165-70.

[102] Marumo T, Nakaki T, Hishikawa K, Suzuki H, Kato R, Saruta T. Cyclosporin A inhibits nitric oxide synthase induction in vascular smooth muscle cells. Hypertension 1995;25(4 Pt 2):764-8.

[103] Grieff M, Loertscher R, Shohaib SA, et al. Cyclosproine-induced elevation in circulating endothelin-1 in patients with solid-organ transplants. Transplantation 1993;56:880-4.

[104] Perico N, Zoja C, Benigni A, Ghilardi F, Gualandris L, Remuzzi G. Effect of short-term cyclosporine administration in rats on reninangiotensin and thromboxane A2: possible relevance to the reduction in glomerular filtration rate. J Pharmacol Exp Ther 1986;239:229-35.

[105] Smith SR, Creech EA, Schaffer AV, Martin L, Rakhit A, Douglas FL, et al. Effects of thromboxane synthase inhibition with CGS 13080 in human cyclosporine nephrotoxicity. Kidney Int 1992;41:199-205.

[106] Mihatsch MJ, Ryffel B, Hermle M, et al. Morphology of cyclosproine nephrotoxicity in the rat. Clin Nephrol 1986;25(Suppl 1):S2-8.

[107] American Diabetes Association. Diabetes 2001 Vital Statistics. Alexandria, VA: American Diabetes Association; 2001.

[108] Folsom AR, Szklo M, Stevens J, Liao F, Smith R, Eckfeldt JH. A prospective study of coronary heart disease in relation to fasting insulin, glucose, and diabetes. The Atherosclerosis Risk in Communities (ARIC) Study. Diabetes Care 1997;20:935-42.

[109] Curb JD, Pressel SL, Cutler JA, Savage PJ, Applegate WB, Black H, et al. Effect of diureticbased antihypertensive treatment on cardiovascular disease risk in older diabetic patients with isolated systolic hypertension. Systolic Hypertension in the Elderly Program Cooperative Research Group. JAMA 1996;276:1886-92.

[110] Hypertension Detection and Follow-up Program Cooperative Research Group (HDFP). Mortality findings for stepped-care and referred-care participants in the hypertension detection and follow-up program, stratified by other risk factors. Prev Med 1985;14:312-35.

[111] Wang JG, Staessen JA, Gong L, Liu L. Chinese trial on isolated systolic hypertension in the elderly. Systolic Hypertension in China (Syst-China) Collaborative Group. Arch Intern Med 2000;160:211-20.

[112] Hansson L, Zanchetti A, Carruthers SG, Dahlof B, Elmfeldt D, Julius S, et al. Effects of intensive blood-pressure lowering and low-dose aspirin in patients with hypertension: principal results of the Hypertension Optimal Treatment (HOT) randomised trial. HOT study group. Lancet 1998; 351(9118):1755-62.

[113] Tuomilehto J, Rastenyte D, Birkenhager WH, Thijs L, Antikainen R, Bullpitt CJ, et al. Effects of calcium-channel blockade in older patients with diabetes and systolic hypertension. Systolic Hypertension in Europe Trial Investigators. N Engl J Med 1999;340:677-84.

[114] Bakris GL. Maximizing cardiorenal benefit in the management of hypertension: achieve blood pressure goals. J Clin Hypertens 1999;1:141-7.

[115] United Kingdom Prospective Diabetes Study 39: Efficacy of atenolol and captopril in reducing risk of macrovascular and microvascular complications in type 2 diabetes. UKPDS. BMJ 1998;317: 713-20.

[116] Hansson L. Recent intervention trials in hypertension initiated in Sweden-HOT, CAPP and others. Hypertension Optimal Treatment Study. Captropril Prevention Project. Clin Exp Hypertens 1999;21:507-15.

[117] Estacio RO, Schrier RW. Antihypertensive therapy in type 2 diabetes: implications of the appropriate blood pressure control in diabetes (ABCD) trial. Am J Cardiol 1998;829B:9R-14R.

[118] Heart Outcomes Prevention Evaluation (HOPE) Study Investigators. Effects of ramipril on Cardiovascular and microvascular outcomes in people with diabetes mellitus: results Of the HOPE study and MICRO-HOPE substudy. Lancet 2000;355:253-9.

[119] Ravid M, Brosh D, Levi Z, Bar-Dayan, Ravid D, Rachmani R. Use of enalapril to attenuate decline in renal function in normotensive, normoalbuminuric patients with type 2 diabetes mellitus. A randomized, controlled trial. Ann Intern Med 1998;128(12 Pt 1):982-8.

[120] Zuanetti G, Latini R. Impact of pharmacological treatment on mortality after myocardial infarction in diabetic patients. J Diabetes Complications 1997; 11:131-6. 